Volume 8 | Issue 1

$11-1-2020$

\title{
Talking About Abortion (Listening Optional)
}

Jennifer W. Reynolds

University of Oregon School of Law, jwr@uoregon.edu

Follow this and additional works at: https://scholarship.law.tamu.edu/lawreview

Part of the Law and Gender Commons, Law and Society Commons, and the Supreme Court of the United States Commons

\section{Recommended Citation}

Jennifer W. Reynolds, Talking About Abortion (Listening Optional), 8 Tex. A\&M L. Rev. 141 (2020). Available at: https://doi.org/10.37419/LR.V8.I1.4

This Article is brought to you for free and open access by Texas A\&M Law Scholarship. It has been accepted for inclusion in Texas A\&M Law Review by an authorized editor of Texas A\&M Law Scholarship. For more information, please contact aretteen@law.tamu.edu. 


\title{
TALKING ABOUT ABORTION (LISTENING OPTIONAL)
}

\author{
by: Jennifer W. Reynolds*
}

\begin{abstract}
Whether we can expect others to listen-and whether we choose to listen to others-have become central challenges in handling conflicts around polarized and high-profile political matters. For those who study alternative dispute resolution ("ADR"), these concerns about listening hit especially close to the bone because they implicate some of the most foundational precepts of dispute resolution practice. This paper explores some of these implications in the context of the fight over reproductive rights, with special focus on the "listening dilemma" that people experience when navigating extremely difficult conversations around crucial political entitlements, especially when those entitlements are in the process of being made and unmade. Paying closer attention to the listening dilemma and other unusually challenging dynamics in public conflicts makes plain the importance of social context when deciding what interventions may be applicable or appropriate. As it turns out, these interventions include listening-but not as dogma and only to the extent that listening makes sense, given goals and context.
\end{abstract}

\section{TABle of Contents}

I. InTROdUCtION..................................... 141

II. The Listening Dilemma ..................... 145

III. An Illustrative Context: The Fight Over Reproductive Rights......................... 147

A. Disorganized Exchange ...................... 150

B. Emotional Content ........................ 153

C. Strategic Opportunism .......................... 155

IV. Managing the Listening Dilemma .............. 157

V. Conclusion .................................. 162

\section{INTRODUCTION}

Margaret Atwood's 1985 novel, The Handmaid's Tale, takes place in Gilead, an oppressive and misogynistic state emerging in the not-sodistant future after fundamentalist militants destroy the United States capitol and impose their vision of the ideal society on the American

DOI: https://doi.org/10.37419/LR.V8.I1.4

* Associate Professor and Associate Dean for Faculty Research and Programs, University of Oregon School of Law; J.D., Harvard Law School; M.A., University of Texas at Austin; A.B., University of Chicago. I have benefitted tremendously from working through this paper with my amazing friends and colleagues who attended the University of Oregon Experimental ADR Conference, taking place in Portland in February 2020. Special thanks to Noam Ebner for his help. Many thanks to the wonderful editors of the Texas A\&M Law Review for their expert assistance. And as always, I am grateful for the support of the University of Oregon School of Law. 
people. ${ }^{1}$ In Gilead, men are in charge, women are not allowed to read, dissenters are tortured and executed, and children are a much-soughtafter commodity. Low birthrate has become a global crisis, and because many of the Commanders (the reigning male class) and their Wives are incapable of having children themselves, they must rely on Handmaids. Handmaids wear long red dresses and white-winged bonnets. They are household servants who are forced to have ritualized sex with Commanders and bear children on behalf of the Commanders' Wives. Any claim the Handmaids have to these children is forsaken, and in Gileadean society the Handmaids are at once esteemed for their fertility and denigrated as sluts.

The Testaments, Atwood's 2019 sequel to The Handmaid's Tale, is the story of how Gilead comes undone. ${ }^{2}$ One of Gilead's chief operatives, a woman of influence in family planning and domestic affairs, decides to go deep undercover for decades to collect information that will prove damaging to the regime. During this time, she manages to cultivate (and often blackmail) allies, spread misinformation, manipulate powerful actors, maneuver unwitting pawns, exploit policies and processes, hide tiny microphones, and-importantly-document, document, document. Eventually, she amasses an incredible dossier of "all the sins of Gilead": ${ }^{3}$ the sexual subjugation of women, the brutality shown to dissenters, the corruption of the legal system, and the depredations and hypocrisy of the Commanders. ${ }^{4}$ Her plan is to store this information in a tiny pellet called a "microdot" that can be carried under the skin. ${ }^{5}$ All she needs is someone to carry the microdot over the border into Canada, on the theory that once the people of the free world can see hard evidence of what is happening in Gilead, Gilead will be unable to prevent its own destruction. ${ }^{6}$

1. See generally Margaret Atwood, The Handmaid's Tale (1985).

2. See generally Margaret Atwood, The Testaments (2019).

3. Id. at 277.

4. Id. at 307. Examples from the dossier: "Handmaids had been forced into illegal acts, then blamed for them; Sons of Jacob had plotted against one another; bribes and favours had been exchanged at the highest levels; Wives had schemed against other Wives; Marthas had eavesdropped and collected information, and then sold it; mysterious food poisonings had occurred, babies had changed hands from Wife to Wife on basis of scandalous rumours that were, however, unfounded. Wives had been hanged for adulteries that had never occurred because a Commander wanted a different, younger Wife. Public trials-meant to purge traitors and purify the leadershiphad turned on false confessions extracted by torture. Bearing false witness was not the exception, it was common. Beneath its outer show of virtue and purity, Gilead was rotting." Id.

5. Id. at 360 .

6. Id. at 404. As it turns out (spoiler alert!), this plan works. The microdot makes it to Canada and indeed is "instrumental in initiating the final collapse of Gilead." Id. at 411. Contained within the microdot were "a great many discreditable personal secrets pertaining to various high-level officials" that, once revealed, led to riots and the eventual overthrow of the Gileadean government. Id. Before the microdot, people outside and inside of Gilead did not really know what was going on-but once they knew the truth, they acted decisively and brought down an unjust state. 
The Handmaid's Tale has been made into a popular television show currently airing, and both the novel and the show resonate with many today, given the modern political landscape. ${ }^{7}$ The story's depiction of how quickly people can lose their rights in society-including the rights of women to make their own choices around whether to bear children-has been called "eerily prescient," 8 with some observing "disconcerting parallels" between Atwood's fictional world and the United States after the 2016 presidential election. ${ }^{10}$ For her part, Atwood resisted the idea that The Handmaid's Tale was predictive, preferring instead to characterize the story as "antiprediction," meaning that "[i]f this future can be described in detail, maybe it won't happen." "Antipredictive thinking is indeed central to the narrative logic of The Testaments, where making detailed information public is the key to progressive legal and political change. ${ }^{12}$ If people are told the truth, Atwood suggests, they will listen. ${ }^{13}$

But is this really the case? ${ }^{14}$ Women's reproductive rights are again in jeopardy as the Supreme Court continues moving to the right and state legislatures enact increasingly draconian measures around access to abortion. ${ }^{15}$ Activists on both sides of the debate, believing that "the time is now," 16 have started stepping up their efforts to influence po-

7. See Jennifer Keishin Armstrong, Why The Handmaid's Tale Is So Relevant Today, BBC (Apr. 25, 2018), http://www.bbc.com/culture/story/20180425-why-thehandmaids-tale-is-so-relevant-today [https://perma.cc/CGX4-QEK7] (citing Joyce Carol Oats in a 2006 interview).

8. See id.

9. See Jonah Waterhouse, The Creepy Ways Gilead in 'The Handmaid's Tale' Resembles Trump's America, Elle Austl. (June 29, 2018, 1:19 AM), https://www.elle .com.au/culture/handmaids-tale-gilead-america-17941 [https://perma.cc/NK95-26UR].

10. Id.

11. Margaret Atwood, Margaret Atwood on What 'The Handmaid's Tale' Means in the Age of Trump, N.Y. Times (Mar. 10, 2017), https://www.nytimes.com/2017/03/ 10/books/review/margaret-atwood-handmaids-tale-age-of-trump.html [https://perma .cc/E6HE-YLFB].

12. See generally Atwood, supra note 2.

13. Id.

14. In her review of The Testaments, Deborah Friedell observed that, in real life, simply providing information may not be enough to remove a corrupt and sexist regime. Deborah Friedell, I Love Her to Bits, London Rev. Books (Nov. 7, 2019), https://www.lrb.co.uk/the-paper/v41/n21/deborah-friedell/i-love-her-to-bits [https:// perma.cc/S5ZA-LA82]. "It might once have been the case that all it would take to bring down a ruler was clear evidence of his corruption. If The Testaments were truly a novel for our times, after Aunt Lydia and her allies had succeeded in getting the documents out, after having risked, as they do in Atwood's book, discovery and death in almost every chapter, journalists would write about them; and nothing would happen." Id.

15. See Sabrina Tavernise, 'The Time Is Now': States Are Rushing to Restrict Abortion, or to Protect It, N.Y. Times (May 15, 2019), https://www.nytimes.com/2019/05/15/ us/abortion-laws-2019.html [https://perma.cc/N6VP-R54S]; infra note 55.

16. See id. 
litical actors and institutions. ${ }^{17}$ And with the presidential election around the corner, views on abortion (especially with regard to possible judicial appointments) are sure to be high-profile points of contrast between the candidates. ${ }^{18}$ In this fast-changing context, figuring out how to engage the polity and the policymakers on questions of reproductive rights is of paramount importance. Providing information and hoping people will listen - what we might call "the microdot strategy"-may be helpful in this engagement insofar as providing information makes it possible to lay bare the personal stories of those affected by the issue; the track record of state action when it comes to women and children; the narrative impacts of activism and rhetoric; the shifting political agendas of powerful actors; the misinformation spread by extremists; and the serious individual and societal consequences of regulating reproductive freedoms. ${ }^{19}$ But will simply providing information actually move the needle in how people think and vote? In other words, will people listen?

Addressing this question in the context of the fight over reproductive rights serves as a useful case study for assessing the benefits and challenges of listening in this and other highly partisan and pressing political disputes. The notion that listening may be optional leads to important questions about the role of dispute resolution and the limits of political imagination. Following this introduction, the next Part introduces and defines the "listening dilemma"-an unavoidable aspect of hotly contested public disputes that arises whenever the prospect of listening in a conflict situation appears potentially beneficial and potentially harmful at the same time. The Article then situates the listening dilemma within the framework of the abortion debate by demonstrating how features of that debate make it particularly important yet difficult for advocates to embrace listening as a strategy. Finally, the Article explores some possible ways to work through the listening dilemma. Like all dilemmas, the listening dilemma cannot be solved or eliminated; it can only be managed. Figuring out how to

17. See, e.g., Erin Corbett, 21 Abortion Restrictions Have Already Been Enacted in 2019. More Are Coming, ForTune (Apr. 23, 2019, 10:03 AM), https://fortune.com/ 2019/04/23/new-abortion-laws-2019/ [https://perma.cc/FP46-DUJ8].

18. See, e.g., Stephanie Saul, Democrats Discuss Abortion Rights in Depth at Debate, N.Y. Times (Feb. 7, 2020), https://www.nytimes.com/2020/02/07/us/politics/ abortion-litmus-test-debate.html [https://perma.cc/5U7B-PC9K] (describing how Democratic candidates were promising to protect Roe judicially and legislatively); Lauren Egan, Trump Becomes First Sitting President to Attend March for Life Rally, NBC News (Jan. 24, 2020, 1:31 PM), https://www.nbcnews.com/politics/donald-trump/ trump-becomes-first-sitting-president-attend-march-life-rally-n1122246 [https:// perma.cc/4GA8-GLFQ] ("His decision to attend the event on Friday comes as he faces an impeachment trial in the Senate and as he works to shore up his political base ahead of his 2020 re-election campaign.").

19. See, e.g., Anna North, How Abortion Became a Partisan Issue in America, Vox (Apr. 10, 2019, 7:30 AM), https://www.vox.com/2019/4/10/18295513/abortion-2020-roe -joe-biden-democrats-republicans [https://perma.cc/43QS-V9MS]. 
manage this dilemma while remaining true to personal values and political commitments is a pivotal challenge for ourselves and for our democracy.

\section{The Listening Dilemma}

It is hard to overstate the value of listening when it comes to handling conflict (and everything else) effectively. ${ }^{20}$ By listening to others, we gather information and we show respect; both are fundamental to successful conflict management and resolution. ${ }^{21}$ Without information, it is impossible to know what might solve the problem, at least in the sense that an appropriate and durable solution must be tailored to the contours of the interests and values that inform people's perspectives on the situation. ${ }^{22}$ Without respect, it is difficult to reduce the tension between people in conflict and develop solutions that they would be willing to accept. ${ }^{23}$ Moreover, when people truly listen, they make room for adjusting their views, rethinking their commitments, or even changing their minds. ${ }^{24}$ In light of new information, after all, what seemed true before may no longer seem as true. ${ }^{25}$ Setting these transformational possibilities in motion is especially important in highly positional and entrenched disputes. Such disputes derive much of their force from the oppositional energy of seemingly incompatible interests and values. ${ }^{26}$ Open-minded listening, as Jonathan Cohen has argued, builds bridges over these divides and makes possible revelations and even resolution. ${ }^{27}$

But listening in conflict situations is not easy, given that disputants have different ideas around what should happen, and these differences may cause or exacerbate emotional responses that make listening difficult. Additionally, figuring out when and how to listen under these circumstances is not always self-evident. Bob Mnookin and others have described the difficulties in balancing listening and talking

20. Roger Fisher \& William Ury, Getting to Yes: Negotiating Agreement Without Giving In 34 (Bruce Patton ed., 2d ed. 1991).

21. Id.; see also Sara Cobb, Speaking of Violence: The Politics and Poetics of Narrative Dynamics in Conflict Resolution 57 (2013) (defining the "differend" as "the suffering that results from the victimization related to not being heard").

22. See, e.g., Fisher \& URY, supra note 20, at 40.

23. Id. at 54-55; see also Robert H. Mnookin et Al., Beyond Winning: Negotiating to Create Value in Deals and Disputes 49 (2000).

24. See, e.g., Jonathan R. Cohen, Open-Minded Listening, 5 Charlotte L. Rev. 139, 145-47 (2014) (describing the various modalities of listening as well as the "benefits of empathetic listening" for the person being listened to).

25. See Noam Ebner et al., Negotiation 371 (2019) (arguing that active listening helps build trust while setting productive norms for further communication); Douglas Stone et al., Difficult Conversations: How to Discuss What MatTERs Most 30-37 (2d ed. 2010).

26. See Fisher \& URY, supra note 20, at 13.

27. See Cohen, supra note 24, at 146 ("Truly listening to the other side might mean having to face the possibility that, on some points at least, the other side is right."). 
as part of the "tension between empathy and assertiveness," a dynamic that emerges in negotiation and conflict situations. ${ }^{28}$ Empathy, the ability to see the world through the eyes of someone else, requires careful listening for the thoughts and feelings of other people, following up with questions as possible. ${ }^{29}$ Assertiveness, by contrast, is expressing one's own interests and concerns so that the other person can hear and understand them. ${ }^{30}$ Empathy and assertiveness are in tension because the skills required to gather information are not the same as the skills required to express oneself, and pivoting between these modalities can be challenging. ${ }^{31}$

Furthermore, for highly polarized, values-based conflicts with a substantial public dimension-what I have described before as "snap disputes"-listening can seem not just difficult, but unacceptably risky. ${ }^{32}$ In these conflicts, people may not be willing to dialogue in good faith, meaning that they may not express themselves honestly or intend to listen to anyone with whom they disagree. When people will not dialogue in good faith, listening to them seems pointless and potentially harmful to the listener and to anyone witnessing the exchange. ${ }^{33}$ Additionally, in these high-stakes, value-intensive conflicts, some people may hold views that other people consider intolerable as a matter of human rights or individual identity. ${ }^{34}$ When people hold intolerable views, listening to them (and this is especially true when listening in the presence of others) may at best perpetuate false equivalencies, in which all views are deemed equal and worthy of respect, or at worst inflict serious psychic harm. ${ }^{35}$ In both situations (bad faith and intolerable views), people may refrain from listening to avoid the deleterious effects that listening under these circumstances may cause-but this means, of course, that the reciprocity and mutuality required for handling conflict successfully will never materialize.

This is the "listening dilemma." 36 The listening dilemma arises in conflict situations where listening is absolutely essential but also po-

28. MNOOKIN ET AL., supra note 23, at 44-68.

29. See id. at 63 (describing the "empathy loop").

30. Id. at 47.

31. "When faced with conflict, we tend to either advocate forcefully-often too forcefully - our own view or focus on the other side's view, rather than moving nimbly from one skill to the other." Id. at 50.

32. See Jennifer W. Reynolds, Snap Disputes, 25 Harv. Negot. L. Rev. 37, 45 (2019) [hereinafter Snap Disputes].

33. Id. at 74 .

34. Id. at 65 .

35. Id. at 63 ("Accordingly, attempting to handle the conflict through listening may actually lead to greater divisiveness.").

36. The "listening dilemma" is inspired by the concept of the "negotiator's dilemma," in which one must share information in order to create value, but sharing information may leave one open to exploitation. See David A. Lax \& James K. Sebenius, The Manager as Negotiator 30 (1986); Robert H. Mnookin, Why Negotiations Fail: An Exploration of Barriers to the Resolution of Conflict, 8 Онго ST. J. ON DisP. Resol. 235, 239-42 (1993). The negotiator's dilemma is, in turn, inspired by 
tentially destructive. Put another way, when dealing with extremely difficult conflict, one must listen to improve the situation because listening increases knowledge, reduces tension, and bestows respect; but if one listens, one may worsen the situation because listening may delay progress, perpetuate false equivalencies, cause harm, and reward bad faith tactics. ${ }^{37}$ Furthermore, given that assertiveness (speaking and being listened to) is essential in successful conflict management, ${ }^{38}$ the fact that the other side cannot be compelled to listen and likely will not listen, ${ }^{39}$ considering the listening dilemma, makes an already intractable and fractious situation even more so. As such, the listening dilemma contemplates both the risks around listening to others and the difficulties of having others listen to us when stakes are high and conflict is intense.

The listening dilemma helps explain the disconnect that many people feel between their commitment to certain political views and their values around tolerance, inclusivity, viewpoint diversity, and cooperation. ${ }^{40}$ The current fight over reproductive rights provides an opportunity to consider how the listening dilemma plays out in practice. To the extent that people are not listening to one another when it comes to abortion-talking past one another, showing disrespect, being unwilling to examine their positions, engaging in bad faith, espousing intolerant worldviews - it may be that the features of the situation are giving rise to a listening dilemma. Diagnosing how the listening dilemma operates in this context may provide clues as to how to work through the dilemma.

\section{An Illustrative Context: The Fight Over REPRODUCTIVE RIGHTS}

The abortion debate takes place on multiple fronts, ranging from the private to the public. ${ }^{41}$ At one end of the spectrum is the individual who grapples with questions such as when life begins, what control women should have over their bodies, and whether and how the state should be involved in these matters. At the other end are governments creating legal frameworks for regulating reproductive rights, which may involve strengthening protections or criminalizing behaviors. Between these two poles are interactions among people and

the prisoner's dilemma, in which cooperation for mutual gain is unavoidably fraught by the temptation to exploit and the fear of being exploited. See Robert AxELrod, The Evolution of CoOperation 9 (1984).

37. See Cohen, supra note 24 , at 151.

38. See StOne ET AL., supra note 25, at 268.

39. See Cohen, supra note 24, at 151-54.

40. Part of what makes it useful is that many people, myself included, have strong views on reproductive rights even as we believe in inclusive and respectful process. I have tried to write this article to be instructive no matter what one's views might be, but I also want to acknowledge that I am not neutral.

41. See North, supra note 19. 
groups with different agendas, access, interests, values, and levels of investment. These interactions are largely efforts to persuade, in that they seek to change the minds of individuals or push the government to act one way or another. What happens at one end of the spectrum affects what happens at the other, and the motivations behind these interactions often are quite layered and complex. ${ }^{42}$

In many ways, these interactions within the abortion debate are negotiations. This may seem like an odd characterization given that the larger fight around reproductive rights is about creating and enforcing legal regimes that will be imposed on everyone, not engaging in private ordering between parties who agree. ${ }^{43}$ Moreover, many of these interactions do not occur in real time between actual people, and even if they did, it would not be immediately apparent that the interactions were negotiations and not simply disagreements. ${ }^{44}$ Finally, at the macro level, the key events in the abortion debate (who is elected, who is appointed, what laws come into being) are all directly or indirectly voted upon and, as such, are supposedly reflective of whoever has the most leverage and power. In other words, the "decision rules" around how we govern abortion matters are not themselves negotiated between parties but instead are the outcome of legal and political struggle.

But the way that struggle goes is nonetheless the result of many negotiations happening at various levels. In the abortion debate, just as in negotiation generally, no side has the power to impose its will on the other in any sort of permanent way. ${ }^{45}$ Beliefs about abortion are often deeply personal and laden with values. As such, whether the law stays the same or changes, many who are in opposition to the law will find ways to resist and mobilize. Part of this resistance will involve figuring out how to influence others to use their power-their beliefs, their votes, their political involvement, their interpersonal interactions - to have an impact on the larger decision-making process. Conflicts will be inevitable as people attempt to gain ground at the level of law and policy by engaging in difficult conversations and activism. ${ }^{46}$ Participating in these conflicts strategically, in the sense of evaluating the situation and then deploying various techniques in the service of one's preferred outcomes, is a form of negotiation.

42. $I d$.

43. See id.

44. People often think of negotiations as specialized forms of communication meant to lead to gains from trade, like a buyer-seller situation. But any effort to persuade someone to do something (like adopt your viewpoint or change their behavior) may be thought of as negotiation. See, e.g., Jennifer W. Reynolds, The A Is for Activism, in The Negotiator's Fieldbook: The Desk Reference for the Experienced Negotiator (Chris Honeyman \& Andrea Kupfer Schneider eds., 2017) (arguing that activism, as an effort to persuade, may be thought of as negotiation with emphasis).

45. North, supra note 19.

46. See generally Reynolds, supra note 44. 
All that said, interactions about abortion rights certainly do not look like conventional negotiations and vary greatly depending on context. Some of these interactions may resemble conversations, for example, either between people with different views (attempting to persuade the other ${ }^{47}$ ) or among people with similar views (strengthening resolve or inspiring action, like "get out the vote"). These conversations may happen in real time or they may be asynchronous; they may be lengthy exchanges, like arguments at Thanksgiving, or they may be quick information blasts, like seeing a car sporting a pro-life or pro-choice bumper sticker. Other interactions may emerge through publications in media and social media, such as tweets, emails, Snapchats, online comments, blog posts, and articles. Still others may appear as some form of motivated activity, either out in public (protesting, marching, giving speeches) or behind closed doors with decisionmakers (lobbying, letter-writing campaigns). All of these activities may be efforts to persuade and thus fall under the umbrella of negotiation, but they unfold in different ways.

Moreover, seeing the abortion debate through a negotiation lens is challenging for at least three reasons. First, these interactions are much more disorganized than one might expect even from difficult negotiations. They are disorganized in the sense that they generally do not follow a bargaining protocol within a discrete context-something that would bring people together in time and space to exchange information and concessions-but instead exist within a constantly shifting framework of legal entitlements and activist messaging. Second, these interactions are unusually stressful in that they often involve high levels of emotion and life-or-death stakes, which makes the prospect of empathy and finding common ground much more difficult. And third, these interactions are often quite multi-layered, in the sense that people may participate for reasons that are separate from the substance of the matter at hand. Such people may not have any investment in the abortion debate itself, for example, but may behave as though they do because of partisan affinities or in order to gain some other benefit in some other context.

Given these conceptual challenges, why does it matter whether we see interactions within the abortion debate as negotiations? It matters because negotiation theory offers analytical frameworks and practical methods that may benefit those who are engaging in these interactions. ${ }^{48}$ More specifically, seeing the various interactions in the abortion debate as negotiations-and not merely, say, as self-expressioncan provide greater insight into the role of listening in these contexts,

47. Or, depending on the context, attempting to persuade a third-party watching the exchange. See Jennifer W. Reynolds, Does ADR Feel Like Justice?, 88 Fordham L. ReV. 2357, 2359 (2020).

48. See generally Jennifer W. Reynolds, The Activist Plus: Dispute Systems Design and Social Activism, 13 U. St. Thomas L. Rev. 334 (2017). 
particularly given the negotiation field's expansive treatment on the topic of listening. With that in mind, let us look again and more deeply at these three challenges: disorganized exchange, emotional content, and strategic opportunism. Although these certainly are not the only relational and substantive challenges associated with the abortion debate, they provide useful insight into our earlier discussion of the listening dilemma. Put another way, understanding how these three challenges are affecting the negotiations happening within the abortion debate will make it easier to evaluate not only the potential benefits and risks of listening but also the possible forms that effective listening might take.

\section{A. Disorganized Exchange}

As noted above, negotiated interactions within the abortion debate are often spontaneous and asynchronous, taking place in both physical and virtual settings and involving people who may or may not interact directly. These interactions also may involve bots and trolls who, for various reasons, may attempt to inflame emotions and divisiveness within these interactions. ${ }^{49}$ Thus these interactions are highly disorganized in the sense that they do not take place in a controlled setting with identifiable participants exchanging viewpoints and information in a rational manner.

What is more, interactions within the abortion debate take place in a larger context of law and policy that is also unstable. Most nations and states currently have some form of legal abortion, but not all offer similar access or protections, and the regimes themselves are in constant flux. ${ }^{50}$ Here in the United States, abortion rights are currently protected at the federal level as a matter of Supreme Court jurisprudence. ${ }^{51}$ Recent appointments to the federal judiciary, however, have put those protections in jeopardy. ${ }^{52}$ Since 2016, President Trump has

49. See Snap Disputes, supra note 32, at 43-44.

50. See Angelina E. Theodorou \& Aleksandra Sandstrom, How Abortion Is Regulated Around the World, Pew Rsch. CTr. (Oct. 6, 2015), https://www.pewresearch. org/fact-tank/2015/10/06/how-abortion-is-regulated-around-the-world/ [https://perma .cc/R4H4-BKUX] (noting that almost every nation allows women to abort to save their own lives); see also The World's Abortion Laws, CTR. FOR ReProd. Rights, https://reproductiverights.org/worldabortionlaws [https://perma.cc/UZ4X-Q4UF]; $A n$ Overview of Abortion Laws, GuTTMACHER Inst., https://www.guttmacher.org/statepolicy/explore/overview-abortion-laws [https://perma.cc/VGW8-55E3] (describing U.S. abortion laws).

51. Roe v. Wade, 410 U.S. 113 (1973) (providing federal protection for abortion rights). But these rights have been cut back by various decisions over the years. See, e.g., Federal and State Bans and Restrictions on Abortion, Planned Parenthood, https://www.plannedparenthoodaction.org/issues/abortion/federal-and-state-bansand-restrictions-abortion [https://perma.cc/983Q-8D9X].

52. President Donald J. Trump Is Appointing a Historic Number of Federal Judges to Uphold Our Constitution as Written, White House (Nov. 6, 2019), https:// www.whitehouse.gov/briefings-statements/president-donald-j-trump-appointing-historic-number-federal-judges-uphold-constitution-written/ [https://perma.cc/C3EJ- 
nominated and successfully had appointed 2 conservative justices to the Supreme Court and 156 conservative judges to the federal district and appellate benches. ${ }^{53}$ These appointments have emboldened some state legislatures to abandon previous incrementalist efforts ${ }^{54}$ and seek to pass laws that restrict abortion in ways that clearly conflict with existing precedent in an effort to force a review of Roe. ${ }^{55}$ Other state legislatures have taken a different tack, enshrining abortion protections into state law so that any changes at the federal level will not affect people in their states. ${ }^{56}$ In both cases, the legal framework's apparent instability has created incentives to attack or to protect reproductive rights. ${ }^{57}$

B6V7]; see also Ian Millhiser, What Trump Has Done to the Courts, Explained, Vox, https://www.vox.com/policy-and-politics/2019/12/9/20962980/trump-supreme-courtfederal-judges (last updated Feb. 4, 2020, 6:58 PM) [https://perma.cc/V7WK-AHJ7].

53. President Donald J. Trump Is Appointing a Historic Number of Federal Judges to Uphold Our Constitution as Written, supra note 52; see also Millhiser, supra note 52.

54. See, e.g., Ramesh Ponnuru, Pro-Lifers Have Momentum, but They Need to Move Gradually, BLOOMBERG (Apr. 5, 2019, 6:00 AM), https://www.bloomberg.com/ opinion/articles/2019-04-05/abortion-opponents-should-stick-to-incrementalism [https://perma.cc/RE6V-4WMC].

55. See, e.g., Jessica Glenza, Will 2020 Be the Year Abortion Is Banned in the US?, GuARDian (Jan. 21, 2020, 2:00 AM), https://www.theguardian.com/world/2020/jan/20/ us-abortion-rights-ban-2020 [https://perma.cc/6DSC-V34Z]; Eric Levenson, Abortion Laws in the US: Here Are the States Pushing to Restrict Access, CNN, https:// www.cnn.com/2019/05/16/politics/states-abortion-laws/index.html (last updated May 30, 2019, 10:39 AM) [https://perma.cc/E6K2-B64C]; see also Joyce White Vance, Alabama's Abortion Bill Is Not About Alabama. It's About Tossing Roe v. Wade., Wash. Post (May 14, 2019, 3:49 PM), https://www.washingtonpost.com/outlook/2019/05/14/ alabamas-abortion-bill-is-not-about-alabama-its-about-tossing-roe-v-wade/ [https:// perma.cc/U7G7-QRFA] (noting that the bill would ban abortion at any stage of pregnancy, without exceptions).

56. In 2019, for example, New York, Illinois, Vermont, and Maine all passed measures intended to bolster and protect abortion rights. What's Going on in the Fight Over Abortion Rights?, BBC News (June 14, 2019), https://www.bbc.com/news/worldus-canada-47940659 [https://perma.cc/7TCH-4KGY].

57. Indeed, many of the Democrats seeking the party's nomination for president explicitly mentioned their commitment to passing a federal law that would protect abortion better than the current Supreme Court jurisprudence does. See, e.g., Maggie Astor, On Abortion Rights, 2020 Democrats Move Past 'Safe, Legal and Rare', N.Y. Times (Nov. 25, 2019), https://www.nytimes.com/2019/11/25/us/politics/abortion-laws2020-democrats.html [https://perma.cc/4UHU-F4JV] (noting that the candidates support codifying Roe into federal law, allowing Medicaid to pay for abortions, removing funding restrictions for referrals, and nominating pro-choice judges to the federal bench). Additionally, some commentators have suggested that teeing up Roe will galvanize the liberal base and draw more people to the polls in 2020 than otherwise would go. See, e.g., Michael Scherer \& Felicia Sonmez, Abortion Ban Reaction: Democrats Erupt, Republicans Stay Quiet as Both Sides See an Impact in the 2020 Election, WAsh. Post (May 15, 2019, 6:58 PM), https://www.washingtonpost.com/politics/democratic-2020-candidates-warn-roe-v-wade-at-stake-after-alabama-abortion-bans-passage/2019/05/15/f4f77c7a-7719-11e9-bd25-c989555e7766_story.html [https://perma.cc/ 8TYW-ETSJ]. For a recent example of partisan framing within an unstable legal framework, see Matthew Impelli, Are Abortions Considered Elective Procedures During Coronavirus? A State by State Roundup, Newsweek (Apr. 3, 2020, 1:09 PM), https://www.newsweek.com/are-abortions-considered-elective-procedures-during- 
As a result, and somewhat paradoxically, the larger context of the abortion debate feels both dangerously unstable and increasingly entrenched. With legal entitlements at stake and legislative and judicial bodies at state and federal levels eager to join the fray, big changes seem to be in the offing. This in turn creates a sense of critical urgency and "siege mentality," which encourages people to hunker down into positions in an effort to push legal and political matters in the direction they want. Positional tendencies are unavoidable in values-based conflicts like abortion, especially because political questions of this nature cannot be resolved by private consensus. People who are engaged in the debate therefore must resort to attempting to fix the laws in the hope that their beliefs about the way the world should work will be imposed on everyone. Of course, resolving conflict in this manner leads to inherent instability because the resolution does not (cannot) account for incompatible interests and values. ${ }^{58}$

Within or perhaps because of this instability, many people are adopting approaches that are explicitly framed as hardline positions and oriented toward legal resolutions. In general, strong positional approaches neither illuminate the complexity of the issues nor validate the possibility that reasonable people may hold different views. Instead, such approaches attempt to sway the undecided, validate supporters, and vilify those who disagree. Students arguing about abortion in class, for example, may find themselves making uncompromising claims about rights, power, freedom, and morality, even if these claims overstate their positions or alienate those with opposing views. ${ }^{59}$ Activists seeking to push public and political opinion, as another example, may engage in high-profile activities such as marches on Washington and viral social media campaigns. As a third example, proponents working with legislators may draft model legislation on the theory that legislation written in advance and tested by other jurisdictions is much easier for politicians to introduce, explain, and defend. ${ }^{60}$ In each example, those engaged in the abortion debate are

coronavirus-state-state-roundup-1496007 [https://perma.cc/9TRS-KGCZ] (noting that "[n]umerous pro-life groups have ... argu[ed] that halting abortion procedures would allow for medical equipment to be redirected to the COVID-19 pandemic").

58. This is a well-known justification of alternative practices. See, e.g., Carrie Menkel-Meadow, The Trouble with the Adversary System in a Postmodern, Multicultural World, 38 WM. \& MARY L. REv. 5, 7 (1996) (arguing that "[c]ourts, with what I have called their 'limited remedial imaginations,' may not be the best institutional settings for resolving some of the disputes that we continue to put before them") (citation omitted).

59. Even conversations between family members have become acrimonious and positional in the tumult of the current political moment. See, e.g., Kiley Bense, How Politics in Trump's America Divides Families, Atlantic (Nov. 26, 2018), https:// www.theatlantic.com/politics/archive/2018/11/how-politics-in-trumps-america-dividesfamilies/576301/ [https://perma.cc/TJ97-9ZV8].

60. See, e.g., Rui Kaneya, Progressives Borrow Strategy from Anti-Abortion Groups: Use Copycat Legislation, USA TodAy (Sept. 30, 2019), https://www.usatoday.com/in-depth/news/investigations/2019/06/19/abortion-law-progressives-borrow- 
seeking to advance their own agendas inside a coercive legal-judicial setting, not to reexamine their own opinions or to cultivate an inclusive atmosphere.

In terms of the listening dilemma, the disorganized exchange of negotiated interactions within the abortion debate makes listening difficult as a logistical matter and unappealing as a substantive matter. Given the uncertainty around legal entitlements and prohibitions, and with the overwhelming sense that time is short, people will tend to "anchor high" and present their positions as inflexible and uncompromising in an effort to sway the legal resolutions as much as they can. As such, they will not be interested in listening to opposing perspectives that might erode their conviction or encumber their activism.

\section{B. Emotional Content}

The second challenge for negotiated interactions in the abortion debate is the emotional content of these interactions. Dealing with emotions can be quite difficult, whether those emotions belong to you or to someone else. ${ }^{61}$

Needless to say, the emotional content of the abortion debate is extremely high. Many people have strong personal views about whether abortion should be legally permitted or, even if legally permitted, should ever happen. These views are linked to other beliefs around when life begins, what constitutes murder, whether the fetus is separate from the mother, whose responsibility children are, what the status of women in society is or should be, and what kinds of controls are acceptable when it comes to regulating women's bodies. The values at stake do not always align, and it is possible to simultaneously support and disagree with the choice to have an abortion, for oneself or for someone else. Among the various reproductive rights, the right to an abortion is one that women may feel most conflicted about exercising for reasons ranging from the spiritual to the physical and from the personal to the societal.

Moreover, when it comes to the public discourse around abortion, the atmosphere (which has always been heated) has become considerably hotter. ${ }^{62}$ As noted above, many anti-abortion activists have abandoned the incrementalist approach they adopted in the wake of Roe,

winning-strategy-pro-life-groups/1483920001/ [https://perma.cc/P9JW-GDWK]; see also Anne Ryman \& Matt Wynn, For Anti-Abortion Activists, Success of 'Heartbeat' Bills Was 10 Years in the Making, CTr. FOR Pub. InTEgrity (June 20, 2019), https:// publicintegrity.org/politics/state-politics/copy-paste-legislate/for-anti-abortion-activists-success-of-heartbeat-bills-was-10-years-in-the-making/ [https://perma.cc/9EBV$58 \mathrm{~N} 6]$.

61. See Stone ET AL., supra note 25, at 85-90 (explaining how emotions "are often at the heart of difficult conversations").

62. See Glenza, supra note 55. 
instead advocating for dramatic changes to abortion law and policy. ${ }^{63}$ In response, some supporters of abortion rights have ratcheted up their rhetoric, from the \#ShoutYourAbortion movement ${ }^{64}$ to wearing handmaid costumes outside legislatures.$^{65}$ These recent developments build upon long-standing efforts on both sides to tap into the emotions and values of individuals when it comes to defining what reproductive rights mean for women and society ${ }^{66}$ Many of these efforts have concerned themselves with labels, such as pro-life, pro-choice, and prowoman. ${ }^{67}$ These labels operate as emotion-inflaming arguments insofar as they challenge people's identities and perceptions of self. ${ }^{68}$ One side's assertion that it is "pro-life" naturally calls the other side into the position of "anti-life," just as one side's assertion that it is "prowoman" naturally calls the other side into the position of "anti-woman." ${ }^{69}$ No one wants to be anti-life or anti-woman, and one intended effect of these labels is to weaken one's opponent through an indirect ad hominem attack. ${ }^{70}$

High emotional content means that people involved are agitated and impassioned about the issues, which reduces cognitive capacity and makes hearing any challenges to one's worldview difficult. Additionally, many substantive aspects of the abortion debate may trench upon personal experiences and beliefs, which can leave people feeling

63. See, e.g., Glenza, supra note 55; Levenson, supra note 55; see also Vance, supra note 55 .

64. See, e.g., Tamar Lewin, \#ShoutYourAbortion Gets Angry Shouts Back, N.Y. Times (Oct. 1, 2015), https://www.nytimes.com/2015/10/02/us/hashtag-campaign-twit ter-abortion.html [https://perma.cc/8UZB-VVFZ].

65. See, e.g., Emma Grey Ellis, Handmaids Tale Garb Is the Viral Protest Uniform of 2019, Wired (Jun. 5, 2019, 12:10 PM), https://www.wired.com/story/handmaidstale-protest-garb/ [https://perma.cc/B5YU-74NC].

66. See generally Laurie Shrage, Abortion and Social Responsibility: DePOlARIZING THE DeBATE 77-130 (2003) (demonstrating how the "politics of visibility" informed visual propaganda and media campaigns that were highly graphical and affecting).

67. Id. at 80; Kimberly Leonard, 'Pro-Life is Pro-Woman': Anti-Abortion Activists Fight 'Anti-Woman' Caricature, WAsh. Exam'R (Jan. 24, 2020, 3:30 PM), https:// www.washingtonexaminer.com/policy/healthcare/pro-life-is-pro-woman-anti-abortion -activists-fight-anti-woman-caricature [https://perma.cc/6DUC-S8PD].

68. Positioning people within a narrative ("calling them into position") is a common maneuver in conflict. See John Winslade \& Gerald Monk, Narrative Mediation: A New Approach to Conflict Resolution 121-22 (2000).

69. Note that these competing labels expose another emotional layer of the abortion debate, one that is concerned with narrative and meaning. On the one side, we have stories of women who are trying to manage their lives and their bodies as sensibly as they can. Leonard, supra note 67 . On the other, we have stories of profligate women who are refusing to take responsibility for their actions. Id. There is another version of both tales, about a hapless victim (either the pregnant woman or the baby) who is being put into harm's way (by Planned Parenthood, by a Pregnancy Crisis Center) and needs rescuing by the law and lawmakers. Id.

70. Id. And note that challenges to identity are potent weapons in conflict. See STONE ET AL., supra note 25, at 113 (defining the "identity quake"). 
vulnerable and easily hurt. In such a situation, listening to those with opposing views is not only difficult but may be quite painful.

\section{Strategic Opportunism}

A third challenge for negotiated interactions within the abortion debate is strategic opportunism. Despite the high emotional content and strong values present in the debate, some people who appear engaged in the conflict do not really care about the issues but instead have other agendas in mind. These people see the dynamics of the abortion debate as potentially beneficial (that is, an opportunity) when it comes to improving their position vis-à-vis their separate agendas. Such strategic opportunism emerges in two ways: first, as an expression of partisan identity; and second, as a political tactic.

First, strong partisan identities may lead people to take positions on issues, even fraught and highly personal issues like abortion, even when they have no particular investment in those positions or those issues. Partisanship is the "set of beliefs and feelings that culminate in a sense of 'psychological attachment' to a political party." sports fans, partisan political actors fervently want their side to win, sometimes at any cost and often regardless of the substantive issues at stake. ${ }^{72}$ Partisan affinities are persistent and may remain durable even in the face of information that might call into question certain positions held by their groups. ${ }^{73}$ Even though studies show that attitudes about abortion are fairly nuanced across the polity and that more people support reproductive rights than do not ${ }^{74}$ attitudes about abortion rights have become closely linked to partisan identities and, as such, are difficult to influence, especially in the current polarized climate. ${ }^{75}$ In general, Republicans have become the anti-abortion-rights party

71. Leonie Huddy \& Alexa Bankert, Political Partisanship as a Social Identity, Oxford Rsch. EnCYClOPEdia Pol. (May 24, 2017), https://oxfordre.com/politics/ view/10.1093/acrefore/9780190228637.001.0001/acrefore-9780190228637-e-250 [https:// perma.cc/6F3X-4LM2]. Partisanship is a kind of social identity manifesting as the desire to "protect and advance the party's status and electoral dominance." Id.

72. See id.; see also Most Partisans Treat Politics Like Sports Rivalries, Instead of Focusing on Issues, ScienceDaily (Apr. 15, 2015), https://www.sciencedaily.com/re leases/2015/04/150415114024.htm [https://perma.cc/3N8L-ZZCK].

73. See Huddy \& Bankert, supra note 71; see also Jennifer Gerson, Georgia and Ohio's New Abortion Laws Will Hurt Women, but Republicans Only Care About Winning a Political Battle, NBC News (May 10, 2019, 3:35 AM), https://www.nbcnews. com/think/opinion/georgia-ohio-s-new-abortion-laws-will-harm-women-republicansncna1004001 [https://perma.cc/E3FC-9TEM].

74. U.S. Public Continues to Favor Legal Abortion, Oppose Overturning Roe v. Wade, Pew Rsch. CTr. (Aug. 29, 2019), https://www.people-press.org/2019/08/29/u-spublic-continues-to-favor-legal-abortion-oppose-overturning-roe-v-wade/ [https:// perma.cc/W85W-CB76].

75. See, e.g., North, supra note 19; Perry Bacon Jr., The Abortion Debate Isn't as Partisan as Politicians Make It Seem, FiveThirtyEight (Jul. 10, 2018, 7:45 AM), https://fivethirtyeight.com/features/the-abortion-debate-isnt-as-partisan-as-politiciansmake-it-seem/ [https://perma.cc/C73P-LVXN]. 
and Democrats the pro-abortion-rights party. ${ }^{76}$ Those who do not align themselves with their chosen party's positions on particular issues may struggle to figure out how they belong. ${ }^{77}$ For example, although pro-choice Republicans and pro-life Democrats exist, they have little political power in their parties on the issue and may find themselves "shunned by activists on both sides."

Second, some people may affiliate themselves with one side or the other in the abortion debate in the service of unrelated political goals. ${ }^{79}$ Politicians may push for a particular law because they or their constituents believe in the law, but they also might push for a particular law because they want to attract new constituents. ${ }^{80}$ Securing political power by leveraging single-issue voters is a key strategy for many politicians. ${ }^{81}$ For example, before his election in 2016, Trump changed his position on abortion rights (from in favor to against) to appeal to evangelical voters who might otherwise not have voted for someone with Trump's personal history and economic track record. ${ }^{82}$ The incentive to use abortion as a wedge issue to gather voters has become increasingly pronounced in the current political climate. Some commentators argue that many voters today do not vote in their own economic interest but instead focus on secondary, values-based issues

76. Id.

77. See Huddy \& Bankert, supra note 71.

78. Gracy Olmstead, How Abortion Warps Our Politics, N.Y. Times (Feb. 5, 2020), https://www.nytimes.com/2020/02/05/opinion/abortion-trump.html [https:// perma.cc/BBF7-WVN7] ("Both Democrats and Republicans are doubling down on abortion ...."); see also Jessica Mendoza, Is Our Political Divide, at Heart, Really All About Abortion?, Christian SCI. Monitor (Apr. 9, 2019), https://www.csmonitor .com/USA/Politics/2019/0409/Is-our-political-divide-at-heart-really-all-about-abortion [https://perma.cc/699C-V66N].

79. John Forester memorably referred to the "theatrics of participation" in describing how "[s]takeholders posture and bluff, exaggerate and overdramatize demands, and often withhold and hide valuable information" in community conflicts. John Forester, Dealing with Differences: Dramas of Mediating Public DisPUTES 111 (2009).

80. President Trump was a supporter of abortion rights until he ran for president and needed the evangelical vote. See Jonathan Merritt, Why Do Evangelicals Support Donald Trump?, ATLANTIC (Sept. 3, 2015), https://www.theatlantic.com/politics/ archive/2015/09/why-do-evangelicals-support-donald-trump/403591/ [https://perma.cc/ T2N8-RFLY]. He has since redoubled his efforts to appear pro-life, most recently speaking at the anti-abortion March for Life-the first sitting president ever to do so. See Sarah McCammon, President Trump Faces Friendly Crowd at March for Life, NPR (Jan. 24, 2020, 5:27 AM), https://www.npr.org/2020/01/24/798994515/presidenttrump-to-face-friendly-crowd-at-march-for-life [https://perma.cc/848E-FF5S].

81. Georgy Egorov, Single-Issue Campaigns and Multidimensional Politics, SEMANTICS SChOLAR 1, 2, https://pdfs.semanticscholar.org/20c7/c5bf7bbfe3396fe432f537 aee691ed1143dd.pdf [https://perma.cc/5ZHE-WU2T].

82. See, e.g., Robb Ryerse, I Questioned the Sincerity of Donald Trump's Pro-Life Stance. The Response from My Fellow Evangelicals Was Troubling, TIME (Feb. 12, 2020, 5:25 PM), https://time.com/5783257/donald-trump-pro-life-evangelical-voters/ [https://perma.cc/D92H-Z7J2]. 
such as abortion and gun control. ${ }^{83}$ Enterprising politicians thus have an incentive to align themselves with these voters on these issues.

When it comes to negotiation, the problem with strategic opportunism is that it exacerbates the positional character of bargaining and can encourage dysfunctional competitive behaviors. ${ }^{84}$ Strategic opportunists are seeking something other than substantive resolution of the problem, so they have no incentive to share information, generate options, and develop workable proposals. In fact, they have some incentive to avoid these activities because for many strategic opportunists, the existence of conflict suits their interests. Perhaps this helps explain recent misinformation campaigns, like the one claiming that abortion rights proponents want to legalize infanticide. ${ }^{85}$ If winning political contests is all that counts, then engaging in hard bargaining tactics (e.g., telling lies) is an understandable (if risky and potentially counterproductive) choice, because it may pull more allies to your side. $^{86}$

Strategic opportunism is perhaps one of the most pernicious problems that leads to the listening dilemma because it undercuts any efforts to have a human-to-human conversation and creates suspicion around intentions and motives. The ingroup/outgroup dynamics created by political "tribalism" could benefit from genuine listening, insofar as listening can promote empathetic relationships and humanize other people. But navigating these dynamics in the short term seems treacherous, given how divisive the political landscape has become. ${ }^{87}$

\section{Managing the Listening Dilemma}

The listening dilemma, an unavoidable aspect of all highly polarized public conflicts, thus presents logistical and substantive difficulties. For those who study alternative dispute resolution ("ADR"), these difficulties feel particularly profound. Many ADR practices naturally gravitate toward something along the lines of the Atwood "antiprediction" position, in that much dispute resolution is grounded in sharing information through talking and listening. ${ }^{88}$ Airing perspectives, acknowledging emotions, and appreciating differences in values are

83. See Eduardo Porter, How the G.O.P. Became the Party of the Left Behind, N.Y. Times (Jan. 27, 2020), https://www.nytimes.com/interactive/2020/01/27/business/ economy/republican-party-voters-income.html [https://perma.cc/E34D-RC9M].

84. See MnOokin ET AL., supra note 23, at 22-25.

85. See, e.g., Jessica Kwong, Fox News Host Falsely States Democrats Want to 'Kill the Baby After the Baby Is Born' in Latest Infanticide Claim, Newsweek (May 13, 2019, 11:36 AM), https://www.newsweek.com/fox-news-democrats-kill-baby-abortioninfanticide-1423779 [https://perma.cc/XFK7-UVG5].

86. This was the "Leave" strategy during the runup to Brexit. See, e.g., James Kirkup, The Lies and Liars of Brexit, Spectator USA (Dec. 11, 2018, 10:22 AM), https://spectator.us/lies-liars-brexit/ [https://perma.cc/D4Q9-VDCG].

87. See, e.g., Snap Disputes, supra note 32, at 38.

88. In one of the classic ADR texts, Roger Fisher and William Ury recommend focusing on "interests, not positions" and, once the interests have been identified, 
common methods for cultivating empathy and moving disagreements toward resolution. ${ }^{89}$ These methods take time and require considerable investment from parties and facilitators, similar to how the microdot strategy took decades of painstaking work. But what happens when time is short, stakes are high, and partisan identities are strong? In these situations, dialogue (and especially listening) may feel both crucially important and unacceptably risky. ${ }^{90}$

In the abortion debate, the listening dilemma is especially acute because gaining real ground on the issues undoubtedly requires closer attention to the experiences people have and the values they hold around the subject of reproductive rights. No one will be persuaded to change their position if they feel that their perspectives are not taken into account. At the same time-and this is what makes it a dilemma-seeking opportunities to listen to others and share one's own perspective could embolden some people to exploit those opportunities to their own political advantage. The disorganized exchange, high emotional content, and strategic opportunism that characterize the abortion debate all contribute to the listening dilemma in that they encourage positional bargaining and reinforce ingroup/outgroup dynamics that tend to vilify those who disagree.

And frankly, at this point in the debate, both sides may feel like there is nothing more they can learn from or teach the opposition. People have been discussing and arguing about abortion rights for decades, and as a result, many advocates today tend to direct their communication efforts toward the undecided or otherwise impressionable. ${ }^{91}$ This sense of resignation may be compounded by the fact that the discursive environment in the United States has degraded to the point that honest dialogue between people who disagree may seem hopeless. With the increasing distrust of expertise, ${ }^{92}$ the media echo

come up with "options for mutual gain." FISHER \& URY, supra note 20, at 40-80. Both activities require talking and listening.

89. Indeed, a classic ADR response in the face of hot-button topics is creating spaces for information exchange (such as learning conversations or town halls) that make it possible for people to delve more deeply into the complexities of the issues, on the theory that these deep dives will promote better relationships, facilitate more robust models of communication, and possibly lead to substantive agreements. See, e.g., Carrie Menkel-Meadow, The Lawyer as Consensus Builder: Ethics for a New Practice, 70 Tenn. L. Rev. 63, 81 (2002) (describing the existence of innovative processes "used to facilitate 'public conversations' about highly controversial matters such as abortion").

90. See Snap Disputes, supra note 32, at 61-62.

91. See, e.g., Eliza Griswold, The New Front Line of the Anti-Abortion Movement, New Yorker (Nov. 11, 2019) https://www.newyorker.com/magazine/2019/11/18/thenew-front-line-of-the-anti-abortion-movement [https://perma.cc/98GM-NEW7] (describing how vulnerable women in need of health care may be influenced by the "deceptive" practices of pro-life pregnancy crisis centers).

92. See generally William Davies, Nervous States: Democracy and the DeCLINE of REASON (2018). 
chambers that people find themselves within, ${ }^{93}$ the shocking amount of misinformation promulgated by motivated parties, ${ }^{94}$ and human cognitive tendencies to cherry-pick data points based on preexisting beliefs or group identity, ${ }^{95}$ it is no wonder that dialogue and especially listening have begun to feel less effective in public conflicts. ${ }^{96}$

With all this in mind, and assuming that we are not ready to give up entirely on listening in public conflicts, is it possible to work through the listening dilemma? Two strategies that may be helpful in deciding whether and how to listen are paying attention to context, both situational and interpersonal, and reexamining listening with respect to goals. (For our purposes, "listening" here means attempting in good faith to understand where the speaker is coming from. ${ }^{97}$ )

First, paying attention to context means developing a more nuanced appreciation for the situational and interpersonal factors at play. Organizing a protest is not the same as encountering one of your prochoice or pro-life relatives at Thanksgiving. Testifying before Congress is not the same as responding to a tweet. Conversations that happen one-on-one are different than those happening in the classroomit matters who is participating and who is watching. In general, the more private the context and the better known the participants, the more potentially beneficial and less risky listening becomes. Also important is the role people are playing within these interactions, as different roles bring different responsibilities when it comes to listening. ${ }^{98}$ The person mediating between disputing parties must listen carefully to guide the conversation while taking care not to share her own perspective and opinions on the mediation's subject, whereas

93. See, e.g., Jack Shafer \& Tucker Doherty, The Media Bubble Is Worse Than You Think, Politico Mag. (June 2017), https://www.politico.com/magazine/story/ 2017/04/25/media-bubble-real-journalism-jobs-east-coast-215048 [https://perma.cc/ E7UR-VKHL].

94. See, e.g., Denise Grady, 'Executing Babies': Here Are the Facts Behind Trump's Misleading Abortion Tweet, N.Y. TIMEs (Feb. 26, 2019), https://www.nytimes .com/2019/02/26/health/abortion-bill-trump.html [https://perma.cc/UVE4-CK9Z].

95. See, e.g., Kirsten Weir, Why We Believe Alternative Facts, Ам. Рsych. Ass'N (May 2017), https://www.apa.org/monitor/2017/05/alternative-facts [https://perma.cc/ T7NW-RR4B]. The classic study on the topic is Albert H. Hastorf and Hadley Cantril, They Saw a Game; A Case Study, 49 J. Abnormal \& Soc. Psych. 129, 135 (1954), which describes how viewers saw the same football game differently, depending on their team affiliations.

96. I have recently addressed this issue in the context of alternative methods and access to justice. See Reynolds, supra note 47, at 2363 (arguing that the way modern public conflicts play out may lead spectators to conclude that "the best way to respond publicly or even privately to any conflict or dispute ... is to show anger and deny everything and not to listen, engage in dialogue, or demonstrate empathy").

97. Douglas Stone, Bruce Patton, and Sheila Heen describe this kind of listening as an attitude that "move[s] from certainty to curiosity." STONE ET AL., supra note 25, at 37.

98. See, e.g., Jennifer Gerarda Brown, Four Questions About Free Speech and Campus Conflict, 2018 J. Disp. Resol. 45, 46 (2018) (emphasizing the importance of context in assessing campus free-speech conflicts). 
the parties in mediation are encouraged to listen to one another so that they can empathize, give and receive validation, see the bigger picture, and perhaps figure out how to handle the conflict. In short, considerations of audience, setting, relationships, and roles are foundational to having a clearer picture of context when deciding whether and how to listen. ${ }^{99}$

Second, it is helpful to see listening as a strategic choice with different possible elaborations, not as a reflexive and unvarying practice. ${ }^{100}$ As described above, the interactions happening within the abortion debate are negotiations, and, like all negotiations, questions of strategy and engagement are paramount. Thinking about the possible reasons for listening in negotiation illuminates the many different purposes that listening can serve, such as learning from someone else, empathizing with and making the other feel heard, cultivating reciprocity, and modeling effective process. These purposes may take different shapes depending on the context and goals. For example, if the goal is to win an argument, then listening to learn the other's talking points makes it possible to craft a more tailored response. If the goal is to deemphasize partisan identities in an abortion-related discussion, then listening to make the other feel heard may create some room for movement on the issue. If the goal is to have a meaningful conversation about the issues and possibilities, then listening to cultivate reciprocity and model effective process may be useful. In all of these cases, the manner and intensity of listening may vary-listening to respond, for example, is not the same as listening to show respect or listening to reexamine the issue-but in each case, listening is a strategic choice that reflects the listener's goals. Accordingly, being mindful of goals can provide insight into whether and how to listen.

Finally, it is important to interrogate the assumptions that inform our understanding of both context and strategy as we manage the listening dilemma. For example, the choice to "deplatform"101 or "cancel" 102 others (two examples of aggressively not listening) comes from our commitment to our values and represents a strategic decision around what will best promote those values in the context of a particular political debate. But this decision also reflects a cultural narrative

99. Also relevant but outside the scope of this Article are considerations of institutional dynamics, structural oppression, and systemic inequities.

100. As Lydia Nussbaum has written in the context of the foreclosure crisis, "While ADR processes [such as listening] offer methods for pushing back against injustice, they too, like any other human invention, can introduce new problems." Lydia Nussbaum, ADR, Dynamic (In)justice, and Achieving Access: A Foreclosure Crisis Case Study, 88 Fordham L. Rev. 2337, 2338 (2020).

101. For a definition and defense of deplatforming, see Jason Koebler, Deplatforming Works, VICE (Aug. 10, 2018, 12:02 PM), https://www.vice.com/en_us/article/ bjbp9d/do-social-media-bans-work [https://perma.cc/2RQJ-ENJP].

102. Aja Romano, Why We Can't Stop Fighting About Cancel Culture, Vox, https:// www.vox.com/culture/2019/12/30/20879720/what-is-cancel-culture-explained-historydebate (last updated Aug. 25, 2020, 12:03 PM) [https://perma.cc/4HWB-A9BY]. 
that assigns people to roles (hero, victim, villain) and imagines political disagreements as hard-fought battles. Real people are more complicated than these stereotypes admit and battles certainly are not the only or best way to address disagreements. ${ }^{103}$ If we sincerely desire lasting change in a particular political arena, we know that this means changing hearts and minds, not just changing laws. ${ }^{104}$ But if we want them to listen with an open mind, might that mean we must do the same?

Note that both of these approaches to the listening dilemma-assessing social context and engaging in strategic decision-making-present two important caveats. First, simply knowing about these approaches does not resolve the listening dilemma. Considerations of context and strategy simply inform choices around listening, to what extent and for what reason. These choices are subject to modification, given changes in information or circumstances. Bad faith or strategic opportunism may not be apparent at the start of an exchange, for example, but once it becomes apparent, the listener may decide to adjust their listening approach or disengage entirely. Second, because these techniques necessarily require more agency on the part of people facing the dilemma, we may see increased incoherence in dispute resolution theory and practice. Whenever something becomes less prescriptive and more intentional, whenever individuals begin to exercise more agency, there is necessarily less consistency around expert recommendations and best practices. As a result, practice norms and ethical constraints may become more differentiated and complex, which could lead to some confusion for people considering their choices around listening (not to mention confusion for people theorizing and teaching in ADR). ${ }^{105}$ That said, such incoherence may be entirely consistent with self-determination, which presumes that people are capable of choosing how they interact and what outcomes they

103. Refusing to listen to people may have short-term benefits, but in the long run, those same people will still be around. If we cannot imagine interacting with one another, is the only solution to separate ourselves? Consider the example of some conservation Oregon counties that are attempting to redraw state lines so that they can be part of Idaho, a red state, instead of staying in Oregon, a blue state. See, e.g., Kristin Lam, Secession in the Pacific Northwest? Some Oregon Residents Petition to Join Idaho, USA TodAy (Feb. 17, 2020, 8:01), https://www.usatoday.com/story/news/ nation/2020/02/17/oregon-idaho-border-petition-secede/4789936002/ [https://perma.cc/ 6QZH-EGWF]. This development is a dramatic example of the consequences that may flow from deciding not to deal with people who think differently.

104. During her presidential run in 2016, Hillary Clinton told Black Lives Matter activists that she was interested in changing laws, not hearts. Russell Berman, Hillary Clinton's Blunt View of Social Progress, Atlantic (Aug. 22, 2015), https://www.the atlantic.com/politics/archive/2015/08/hillary-clintons-blunt-view-of-social-progress/ 402020/ [https://perma.cc/USL9-LLZG]. Emphasizing law makes sense-after all, certain issues require legal action for fair and just determination-but that does not mean hearts are not important to consider. See, e.g., id.

105. See Snap Disputes, supra note 32, at 72-73 (explaining how ADR ethics need to accommodate the concerns of the modern conflict landscape). 
accept. ${ }^{106}$ With that in mind, some philosophical and practice incoherence may be the price we pay for more intentional, thoughtful interactions in polarized debates.

\section{Conclusion}

Trying to engage in dialogue may seem useless (and maybe even a little quaint) in the face of polarized political conflicts. Given the infrastructure of the abortion debate and the apparently incompatible interests of everyone involved, for example, it is very difficult to imagine how matters could proceed in an integrative or dialogic manner, and it is very easy to imagine how listening to the opposition could create unacceptable delays, promote false equivalencies, and bolster bad actors. But the answer cannot be not to listen, because without listening there can be no lasting conflict resolution, no authentic participatory governance, and no real progress on matters that require large-scale cooperative effort.

The listening dilemma, then, is more than just a feature of public conflict. The dilemma serves as both a reminder and an opportunity. It is a reminder that we should never assume without thinking that listening is a waste of time or that listening is a magic potion. It is an opportunity to reexamine what we know about a given conflict and reimagine what strategies we might try. Thus, the listening dilemma serves to sharpen our engagement in political life consistent with our values around justice and peace.

106. Such thinking is consistent with mediation generally, see generally ModEL Standards of Conduct for Mediators (Am. Arb. Ass'n, Am. Bar Ass'n, \& Ass'N FOR CONFLict Resol. 2005), and with the philosophy and practice of narrative mediation more specifically, see WinsLAdE \& MonK, supra note 75, at 158 ("The spirit of the narrative mediation style is embodied in always speaking to people as if they are subjects, or active rather than passive, or creators of meaning rather than just recipients or objects of it. This is a deeply respectful way of speaking."). 